\title{
DOWNSCALING OF SMAP SOIL MOISTURE PRODUCT BY DATA FUSION WITH VIIRS LST/EVI PRODUCT
}

\author{
Xia Lei ${ }^{1}$, Yuxiang Wang ${ }^{1}$, Tao Guo ${ }^{1}$ \\ ${ }^{1}$ PIESAT Information Technology Co., Ltd., Beijing, China - (leixia, wangyx, guotao)@ piesat.cn
}

\begin{abstract}
KEY WORDS: Soil Moisture, Downscaling, SMAP, VIIRS, LST-EVI Triangular Space
\end{abstract}
\begin{abstract}
:
Soil moisture is an essential variable of environment and climate change, which affects the energy and water exchange between soil and atmosphere. The estimation of soil moisture is thus very important in geoscience, while at same time also challenging. Satellite remote sensing provides an efficient way for large-scale soil moisture distribution mapping, and microwave remote sensing satellites/sensors, such as Soil Moisture and Ocean Salinity (SMOS), Advanced Microwave Scanning Radiometer (AMSR), and Soil Moisture Active Passive (SMAP) satellite, are widely used to retrieve soil moisture in a global scale. However, most microwave products have relatively coarse resolution (tens of kilometres), which limits their application in regional hydrological simulation and disaster prevention. In this study, the SMAP soil moisture product with spatial resolution of $9 \mathrm{~km}$ is downscaled to $750 \mathrm{~m}$ by fusing with VIIRS optical products. The LST-EVI triangular space pattern provides the physical foundation for the microwave-optical data fusion, so that the downscaled soil moisture product not only matches well with the original SMAP product, but also presents more detailed distribution patterns compared with the original dataset. The results show a promising prospect to use the triangular method to produce finer soil moisture datasets (within $1 \mathrm{~km}$ ) from the coarse soil moisture product.
\end{abstract}

\section{INTRODUCTION}

Soil moisture is a key variable of surface and atmospheric system, which plays an important role in the process of precipitation distribution, infiltration, runoff and latent heat flux, etc. (Molero et al., 2016; Mccoll et al., 2017). Estimations of large-scale surface soil moisture distribution can be applied to flood and drought monitoring, numerical weather forecasting, climate risk assessment, and crop growth modelling (Robinson et al., 2008; Martinez et al., 2016; Anna et al., 2018).

Microwave remote sensing has been proved to be one of the most effective technique for studying the spatial distribution of soil moisture on a large scale (Rogier et al., 2014). Active microwave (radar) remote sensing has higher spatial resolution and stronger penetration, but is always with long revisit period and high cost, and also sensitive to surface roughness and vegetation biomass, resulting in complex data processing and modelling. Therefore, passive microwave remote sensing is still the most widely used method for soil moisture distribution mapping with the advantages of high temporal resolution and low cost.

Global soil moisture products have been developed from observations by several passive microwave satellite remote sensing sensors worldwide, including Soil Moisture and Ocean Salinity (SMOS), Advanced Microwave Scanning Radiometer (AMSR-1/2), and Soil Moisture Active Passive (SMAP) satellite. Despite of the significant contribution to global environment and climate change studies, these products is still with relatively coarse footprint (tens of kilometres) due to limited SNR of microwave radiometers, which hinders their application in regional hydrological simulation and hazards (drought/flood) monitoring.

To address this shortage, various downscaling approaches have been proposed to generate high-resolution soil moisture maps from original coarse soil moisture products (Peng et al., 2017;
Nasta et al., 2018). The most commonly adopted scheme is to combine coarse passive microwave products with finer satellite observations by SAR or optical/thermal sensors (Srivastava et al., 2013; Rogier et al., 2014). Others use statistical / hydrological model-based or geographic relationship-based methods for soil moisture downscaling (Mascaro et al., 2010; Ranney et al., 2015). Since the latter approaches always need adequate ground measurements as input to drive a model or establish a relationship, multi-source satellite data fusion is much more frequently used in practice (Das et al., 2011; Chakrabarti et al., 2015).

Compared with the radar backscatter signal recorded by SAR, optical and thermal infrared sensors can provide more closely related information with ground parameters. For example, vegetation index (VI), land surface temperature (LST) and surface albedo are all directly related to soil moisture content (Piles et al., 2016). With the premise that LST is sensitive to soil moisture content as well as vegetation cover, previous researches have introduced the "Universal Triangle Space" pattern between LST and VI to explore regional soil moisture variability (Carlson et al., 1994; Gillies et al., 1997; Sandholt et al., 2002; Chauhan et al., 2003), which have been demonstrated to have good performances.

NASA's SMAP satellite mission was launched on January, 2015, mainly designed for global mapping of soil moisture and landscape freeze/thaw state (Colliander et al., 2017). The satellite is employed with an L-band radiometer, the best choice for soil moisture retrieval using microwave radiometers (Schmugge et al., 1986), which is same with SMOS, but providing a more accurate soil moisture retrieval due to its better antenna design and reduced impact from Radio Frequency Interference (RFI) contamination (Chan et al., 2016).

Therefore, this paper attempts to downscale the SMAP $9 \mathrm{~km}$ product to a footprint within $1 \mathrm{~km}$ by fusing with Suomi NPP VIIRS LST/EVI product. Both satellite missions can provide 
daily products in Level 3, which offers the best compliance for multi-source data fusing. Two triangular methods "Temperature-Vegetation Triangle Method (TRIA)" (Kim and Hogue, 2012) and "Vegetation Temperature Condition Index (VTCI)" method (Peng et al., 2015) are testified and results are compared to identify the better downscaling strategy.

\section{DATA AND METHODOLOGY}

\subsection{Datasets}

2.1.1 SMAP dataset: The SMAP data products are delivered at four levels: instrument measurements (Level 1), geophysical retrievals (swath based, Level 2), daily composite (Level 3), and land surface models assimilating SMAP measurements (Level 4), grided as 36-km, 9-km and 3-km Equal-Area Scalable Earth grid ver. 2 (EASE-2) accordingly (Colliander et al., 2017). The L3_SM_P_E (SMAP Enhanced L3 Radiometer Global Daily 9 $\mathrm{km}$ EASE-Grid Soil Moisture, Version 4) is downloaded from NDISC website (https://nsidc.org/data/smap/smap-data.html). An estimate of the soil moisture in the top $5 \mathrm{~cm}$ of the soil within 50 hours of acquisition is provided by the product. Though the SMAP mission makes daily measurements in the morning and evening (6 AM/6 PM at local time), only the measurements at $6 \mathrm{AM}$ is used. This is because at this time of day, the temperature difference between vegetation and soil is subtle, as well as the difference of thermal radiation among land cover types, which can help to reduce the inversion error of soil moisture (Neill et al., 2020).

2.1.2 VIIRS LST/EVI dataset: The Visible Infrared Imaging Radiometer Suite (VIIRS) instrument, designed as the heritage of the NOAA AVHRR and NASA EOS MODIS, was mounted on the S-NPP satellite and launched on October, 2011. VIIRS data products are distributed in two primary forms: Sensor Data Records (SDRs) (Level 1), and Environmental Data Records (EDRs) (Level 2) (Seaman et al., 2015). The LST/EVI datasets are released as EDR products (VIIRS Land Surface Temperature EDR (VLSTO) and VIIRS Vegetation Index EDR (VIVIO)), providing daily estimations of LST/EVI in $750 \mathrm{~m}$ grids, which can be downloaded from NOAA CLASS website (https://www.avl.class.noaa.gov/saa/products/welcome).

\subsection{Test Area}

Three river basins located across a diversity of climatic and physiographic regions in China are selected as the test area to investigate the potential scalability of the downscaling methods: the Daqing River (Tanghe part) in Haihe River Basin with high intensity of human activities, the Yiluo River in Yellow River Basin as the key flood control region, and the Tangnaihai River in Tibetan Plateau with scarce ground observations (Figure 1).

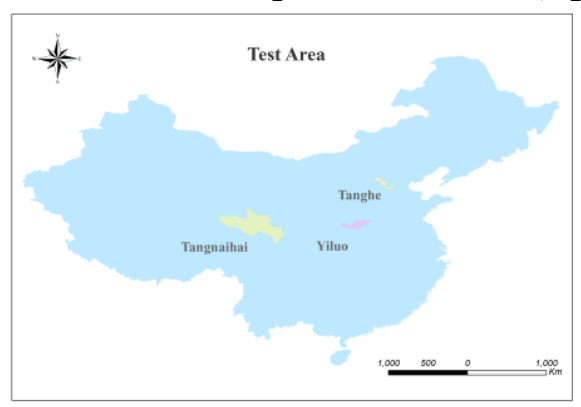

Figure 1. Locations of the three test areas.

\subsection{TRIA Method}

According to Kim and Hogue, 2012, microwave-derived soil moisture can be connected with high-resolution EVI and LST through a regression relationship. In this research, the relationship is expressed by a first-order polynomial regression formula:

$$
S M A P=\alpha \overline{E V I^{*} L S T^{*}}+\beta
$$

where SMAP is the gridded $9 \mathrm{~km}$ SMAP soil moisture product, $\alpha$ and $\beta$ are the slope and intercept, and

$$
\begin{aligned}
& \overline{E V I^{*}}=\frac{1}{m n} \sum_{i=1}^{i=n} \sum_{j=1}^{j=m} E V I^{*}, \\
& \overline{L S T^{*}}=\frac{1}{m n} \sum_{i=1}^{i=n} \sum_{j=1}^{j=m} L S T^{*},
\end{aligned}
$$

where $m$ and $n$ are the ratios of grid size of low-resolution soil moisture product (here is SMAP product) to high-resolution optical product (here is VIIRS EVI/LST product), and $E V I^{*}$ and $L S T^{*}$ are defined as

$$
\begin{gathered}
E V I^{*}=\frac{E V I-E V I_{\min }}{E V I_{\max }-E V I_{\min }}, \\
L S T^{*}=\frac{L S T-L S T_{\min }}{L S T_{\max }-L S T_{\min }},
\end{gathered}
$$

where $E V I$ an $L S T$ are the high-resolution optical products (here is VIIRS EVI/LST product). The subscripts $\max$ and $\min$ represent the maximum and minimum EVI or LST over the study area, respectively.

Finally, the regression coefficients $\alpha$ and $\beta$ in (1) are utilized to estimate the downscaled soil moisture according to

$$
S M A P_{\text {downscaled }}=\alpha E V I^{*} * L S T^{*}+\beta .
$$

\subsection{VTCI Method}

Peng et al., 2015 downscaled the coarse microwave-derived soil moisture product using the vegetation temperature condition index (VTCI):

$$
V T C I=\frac{L S T_{\max }-L S T}{L S T_{\max }-L S T_{\min }}
$$

where the subscripts $\max$ and $\min$ represent the maximum and minimum high-resolution LST (here is VIIRS LST product) that have the same high-resolution EVI value (here is VIIRS EVI product) over the study area. Then the downscaled soil moisture is calculated by

$$
S M A P_{\text {downscaled }}=V T C I * \frac{S M A P}{\overline{V T C I}},
$$

where

$$
\overline{V T C I}=\frac{1}{m n} \sum_{i=1}^{i=n} \sum_{j=1}^{j=m} V T C I
$$




\subsection{Performance Evaluation}

Due to the lack of ground observations in the three test areas at the corresponding time, visual comparison between the downscaled and the original SMAP soil moisture product is made to preliminarily evaluate the performance of two downscaling methods. Comparison of histograms of original SMAP and downscaled products is furtherly made to quantitatively assess the performance of two methods.

\section{RESULTS AND DISCUSSION}

\subsection{Satellite Observations}

Two dates (2019.08.15 and 2020.05.01) are selected when both SMAP and VIIRS mission have observations for the same test area to ensure full data coverage of all the three test areas (Figure 2). Tangnaihai River basin is located at the cross region of two scans of VIIRS mission, where the "Bow-tie effect" exists (Seaman et al., 2015), resulting in the "pixel-trims" within the observations of this area. During the data processing, the pixel-trim is repaired using gdal.FillNodata (GDAL/OGR, 2020).

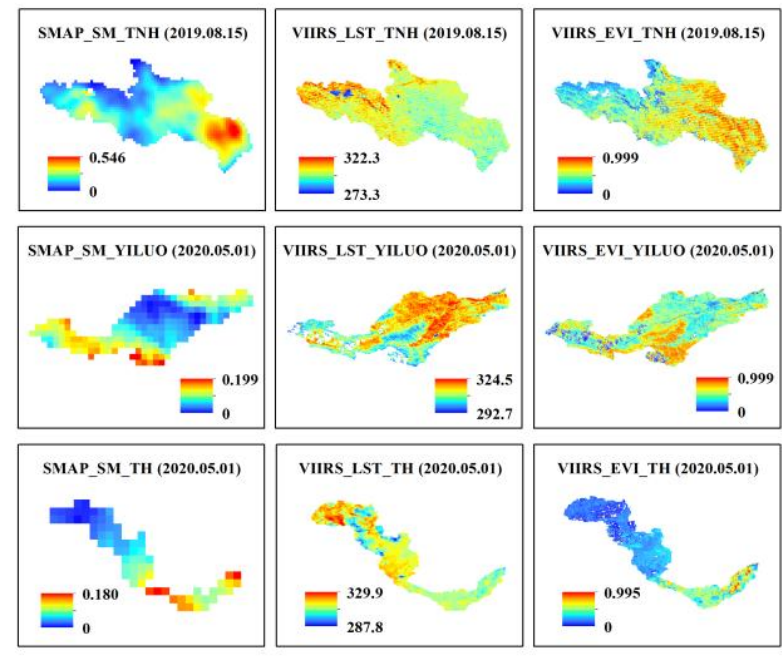

Figure 2. SMAP soil moisture and VIIRS LST/EVI for the three test areas-TNH (short for Tangnaihai River basin),

YILUO (short for Yiluo River basin), and TH (short for Tanghe River basin) on 2019.08.15 and 2020.05.01.

\subsection{LST-EVI Triangular Space}

There are typically two kinds of space patterns between LST and EVI: the triangular space and the trapezoidal space (Tang et al., 2021). Different downscaling methods are applicable for different space patterns. Therefore, the LST-EVI relationship for the three test areas are examined firstly before the downscaling methods are utilized (Figure 3).

Figure 3 indicates the LST-EVI relationship in all three regions are in the triangular space. While the TRIA and VTCI methods are both applicable for the triangular space, thus can be used for soil moisture downscaling in this research.

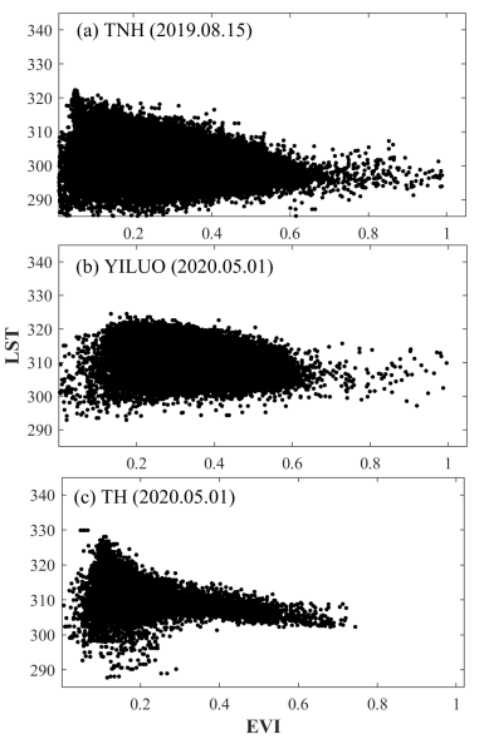

Figure 3. LST-EVI space for the three test areas-TNH (short for Tangnaihai River basin), YILUO (short for Yiluo River basin), and TH (short for Tanghe River basin).

\subsection{Downscaling Results}

3.3.1 TRIA: A polynomial regression relationship is established for each test area according to (1) (Figure 4). Tanghe observation gives the most significant correlation between soil moisture and LST*EVI. The correlation between Tangnaihai observation is generally good, despite that some outliers appear in the scatter plot (Figure 4(a)) deviating severely from the linear relationship line. These outliers tends to be related to the repaired "pixel trims" in the VIIRS LST/EVI product. Then the SMAP soil moisture is downscaled to a footprint of $750 \mathrm{~m}$ by (6) using the linear relationships established in Figure 4, and results are shown in Figure 5.

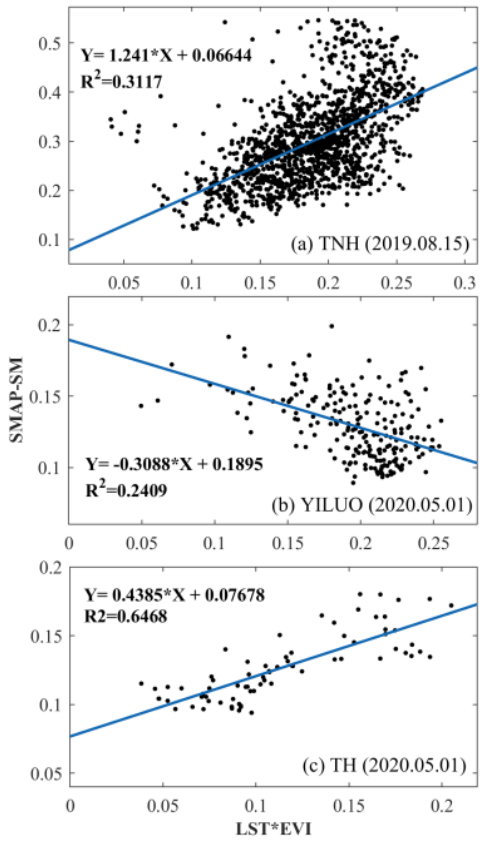

Figure 4. The polynomial regression relationships established for the three test areas-TNH (short for Tangnaihai River basin), YILUO (short for Yiluo River basin), and TH (short for Tanghe River basin). 

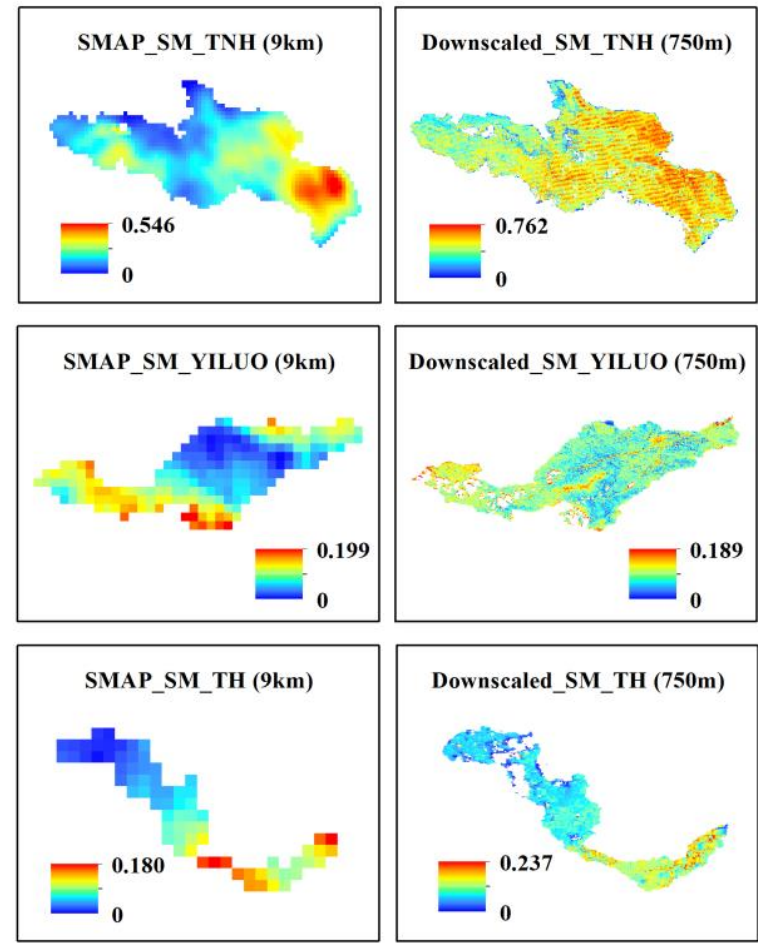

Figure 5. The comparison of original SMAP soil moisture and downscaled soil moisture by TRIA method for the three test areas.

3.3.2 VTCI: Following (7)-(9), the SMAP soil moisture is also downscaled to a footprint of $750 \mathrm{~m}$ (Figure 6).
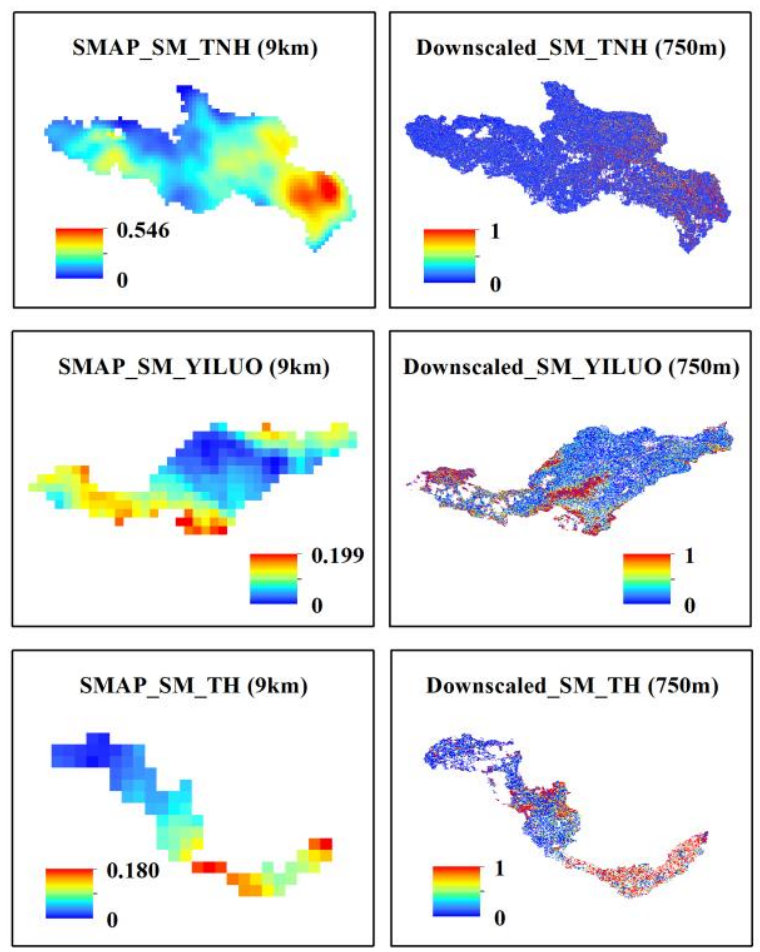

Figure 6. The comparison of original SMAP soil moisture and downscaled soil moisture by VTCI method for the three test areas.

\subsection{Discussion}

Visual comparison of the results of two downscaling methods is straightforward. The TRIA method performs much better than the VTCI method, not only because of the better conservancy of general distribution pattern of soil moisture compared with the original SMAP product, and also the better smoothness and continuity level showed out by the downscaled product. The $750 \mathrm{~m}$ soil moisture maps by TRIA method in Figure 5 reveal much more detailed distribution pattern and much finer variation texture within all three test areas, which illustrates the applicability and scalability of the TRIA method in the downscaling of coarse microwave soil moisture product.

Figure 7 shows the histograms of original SMAP soil moisture and downscaled soil moisture by TRIA and VTCI method for the TNH region. The TRIA method reserves the histogram of original SMAP product, while the VTCI method alters the original histogram a lot, which quantitatively demonstrates the good performance of TRIA method in soil moisture downscaling.
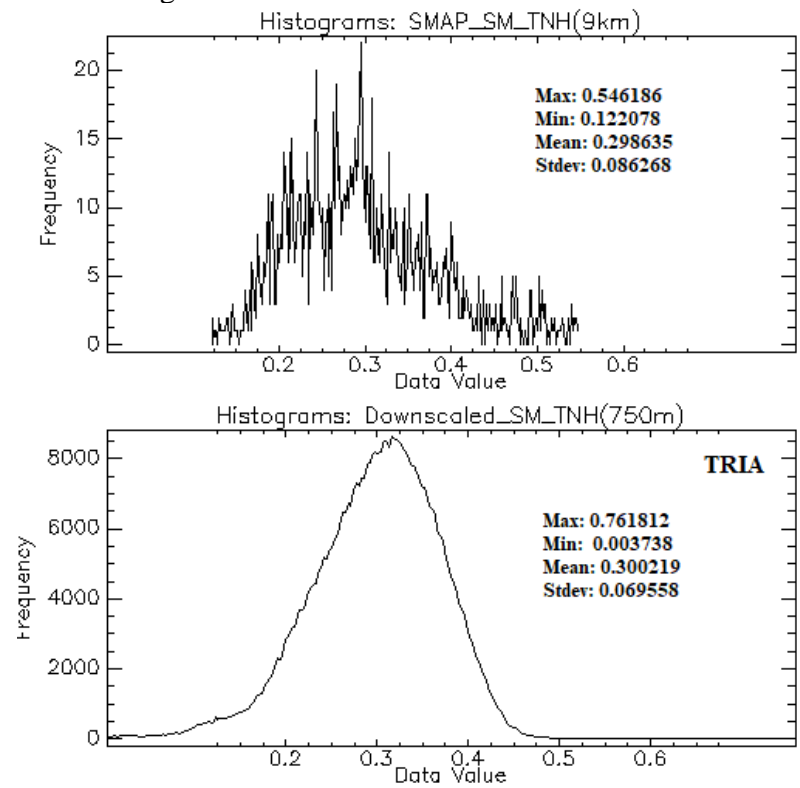

Histograms: Downscaled_SM_TNH(750m)

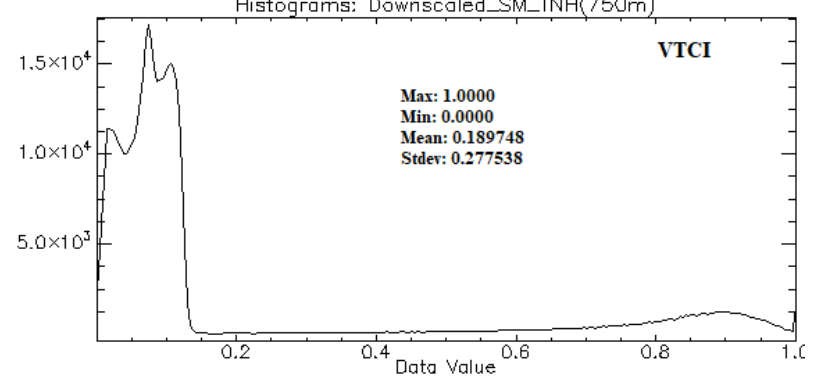

Figure 7. The histograms of original SMAP soil moisture and downscaled soil moisture by TRIA and VTCI method for the TNH region.

\section{CONCLUSION}

In this study, the SMAP soil moisture product with spatial resolution of $9 \mathrm{~km}$ is downscaled to $750 \mathrm{~m}$ by fusing with VIIRS LST/EVI product. Two triangular methods - temperaturevegetation triangle method (TRIA) and vegetation temperature condition index method (VTCI) are testified and compared. The TRIA method shows a promising potential in soil moisture 
downscaling, for the downscaled soil moisture not only matches well with the original SMAP product, but also presents more detailed distribution patterns compared with the original dataset. Although further evaluation and validation with ground observation is still needed, the feasibility to use triangular method to combine the low-resolution microwave product with high-resolution optical observations for the production of finer soil moisture dataset is initially demonstrated.

\section{ACKNOWLEDGEMENTS}

This study is supported by the National Key R\&D Program of China (No. 2018YFE0106500).

\section{REFERENCES}

Anna-Klara, A., Marco, C., Klas, H., Koutsouris, A.J., Crema, S., Zahra, K., 2018: Soil moisture remote-sensing applications for identification of flood-prone areas along transport infrastructure. Environmental Earth Sciences, 77(14), 1-17.

Carlson, T.N., Gillies, R.R., Perry, E.M., 1994: A method to make use of thermal infrared temperature and NDVI measurements to infer soil water content and fractional vegetation cover. Remote Sens. Rev., 52, 45-59.

Chakrabarti, S., Bongiovanni, T., Judge, J., Nagarajan, K., Principe, J.C., 2015: Downscaling satellite-based soil moisture in heterogeneous regions using high-resolution remote sensing products and information theory: a synthetic study. IEEE Transactions on Geoscience and Remote Sensing, 53(1), 85-101.

Chan, S.K., Bindlish, R., O’Neill, P.E., Njoku, E., Jackson, T., Colliander, A., 2016: Assessment of the SMAP passive soil moisture product. IEEE Trans. Geosci. Remote Sens., 54(8), 4994-5007.

Chauhan, N.S., Miller, S., Ardanuy, P., 2003: Spaceborne soil moisture estimation at high resolution: A microwave-optical/IR synergistic approach. Int. J. Remote Sens., 24(22): 4599-4622.

Colliander, A., Jackson, T.J., Bindlish, R., Chan, S., Das, N., Kim, S.B., 2017: Validation of SMAP surface soil moisture products with core validation sites. Remote Sens Rev., 191, 215231.

Das, N.N., Entekhabi, D., Njoku, E.G., 2011: An algorithm for merging SMAP radiometer and radar data for high-resolution soil-moisture retrieval. IEEE Transactions on Geoscience and Remote Sensing, 49(5), 1504-1512.

GDAL/OGR, 2020. Geospatial Data Abstraction Library (GDAL), Version 3.1.3. Open Source Geospatial Foundation. gdal.org (1 September 2020).

Gillies, R.R., Carlson, T.N., Cui, J., Kustas, W.P., Humes, K.S., 1997: A verification of the 'triangle' method for obtaining surface soil water content and energy fluxes from remote measurements of the Normalized Difference Vegetation Index (NDVI) and surface radiant temperature. International Journal of Remote Sensing, 18(15), 3145-3166.

Kim, J., Hogue, T.S., 2012: Improving spatial soil moisture representation through integration of AMSR-E and MODIS products. IEEE Trans. Geosci. Remote Sens., 50(2), 446-460.
Martinez-Fernandez, J., Gonzalez-Zamora, A., Sanchez, N., Gumuzzio, A., Herrero-Jiménez, C.M., 2016: Satellite soil moisture for agricultural drought monitoring: assessment of the SMOS derived soil water deficit index. Remote Sensing of Environment, 177, 277-286.

Mascaro, G., Vivoni, E.R., Deidda, R., 2010: Downscaling soil moisture in the southern Great Plains through a calibrated multifractal model for land surface modeling applications. Water Resources Research, 46(8), 863-863.

Mccoll, K.A., Alemohammad, S.H., Akbar, R., Konings, A.G., Yueh, S., Entekhabi, D., 2017: The global distribution and dynamics of surface soil moisture. Nature Geoscience, 10(2), 100-104.

Molero, B., Merlin, O., Malbeteau, Y., Bitar, A., Cabot, F., Stefan, V., Kerr, Y., Bacon, S., Cosh, M.H., Bindlish, R., Jackson, T.J., 2016: SMOS disaggregated soil moisture product at $1 \mathrm{~km}$ resolution: processor overview and first validation results. Remote Sensing of Environment, 180, 361-376.

Nasta, P., Penna, D., Brocca, L., Zueccod, G., Romano, N., 2018: Downscaling near-surface soil moisture from field to plot scale: A comparative analysis under different environmental conditions. Journal of Hydrology, 557, 97-108.

Neill, P.O., Bindlish, R., Chan, S., Chaubell, J., Njoku, E., Jackson, Tom., 2020: Soil Moisture Active Passive (SMAP) Algorithm Theoretical Basis Document (ATBD) Level 2 \& 3 Soil Moisture (Passive) Data Products. 1-100.

Peng, J., Loew, A., Merlin, O., Verhoest, N.E.C., 2017: A review of spatial downscaling of satellite remotely sensed soil moisture. Reviews of Geophysics, 55(2), 341-366.

Peng, J., Loew, A., Zhang, S., Wang, J., Niesel, J., 2016: Spatial downscaling of satellite soil moisture data using a Vegetation Temperature Condition Index. IEEE Trans. Geosci. Remote Sens., 54(1), 558-566.

Piles, M., Petropoulos, G.P., Sánchez, N., González-Zamora, Á., Ireland, G., 2016: Towards improved spatio-temporal resolution soil moisture retrievals from the synergy of SMOS and MSG SEVIRI spaceborne observations. Remote Sensing of Environment, 180, 403-417.

Ranney, K.J., Niemann, J.D., Lehman, B.M., Green, T.R., Jones, A.S., 2015: A method to downscale soil moisture to fine resolutions using topographic, vegetation, and soil data. Advances in Water Resources, 76, 81-96.

Robinson, D.A., Campbell, C.S., Hopmans, J.W., Hornbuckle, B.K., Jones, S.B., Knight, R., Ogden, F., Selker, J., Wendroth, O., 2008: Soil moisture measurement for ecological and hydrological watershed-scale observatories: a review. Vadose Zone Journal, 7(1), 358 .

Rogier, V.D.V., Salamam M.S., Eweys, O.A., Wen, J., Wang, Q., 2014: Soil moisture mapping using combined active/passive microwave observations over the east of the Netherlands. IEEE Journal of Selected Topics in Applied Earth Observations and Remote Sensing, 8(9), 1-18.

Sandholt, I., Rasmussen, K., Andersen, Jens., 2002: A simple interpretation of the surface temperature/vegetation index space for assessment of surface moisture status. Remote Sensing of Environment, 79, 213-224. 
Schmugge, T., O'Neill, P., Wang, J., 1986: Passive microwave soil moisture research. IEEE Trans. Geosci. Remote Sens., 24(1), $12-22$.

Seaman, C., Hillger, D., Kopp, T., Williams, R., Miller, S., Lindsey, D., 2015: Visible Infrared Imaging Radiometer Suite (VIIRS) Imagery Environmental Data Record (EDR) User's Guide. 1-31

Srivastava, P.K., Han, D., Ramirez, M.R., Islam, Tanvir., 2013: Machine learning techniques for downscaling SMOS satellite soil moisture using MODIS land surface temperature for hydrological application. Water Resources Management, 27(8), 3127-3144.

Tang, R.L., Wang, S.L., Jiang, Y.Z., Li, Z.L., Liu, M., Tang, B.H., Wu, H., 2021: A review of retrieval of land surface evapotranspiration based on remotely sensed surface temperature versus vegetation index triangular/trapezoidal characteristic space. National Remote Sensing Bulletin, 25(1), 65-82. 